\title{
Transmission of solar radiation through the snow cover on floating ice
}

\author{
Onni JÄRVINEN, Matti LEPPÄRANTA \\ Department of Physics, University of Helsinki, Erik Palmenin aukio 1, PO Box 48, FIN-00014 Helsinki, Finland \\ E-mail: onni.jarvinen@helsinki.fi
}

\begin{abstract}
Spectral measurements of solar radiation in the band $400-900 \mathrm{~nm}$ were performed above and inside the snowpack in two locations in Finland, using a spectroradiometer. The transmittance and extinction coefficient were estimated for different snow layers. Four small candle-shaped photosynthetically active radiation (PAR) sensors were also used to measure the transfer of PAR inside the snowpack. In addition to the light measurements, physical characterization of snow stratigraphy was done, including the thickness, density, hardness (hand test), salinity, and grain size and shape (photographs of crystals). The transmittance varied from $<1 \%(0-12 \mathrm{~cm}$ layer) to $80 \%(0-4 \mathrm{~cm}$ layer), and the extinction coefficient was between $0.03 \mathrm{~cm}^{-1}\left(4-8 \mathrm{~cm}\right.$ layer) and $0.8 \mathrm{~cm}^{-1}(0-4 \mathrm{~cm}$ layer). The physical properties of the snow varied considerably between locations and days. The density of the snow varied between 140 and $480 \mathrm{~kg} \mathrm{~m}^{-3}$.
\end{abstract}

\section{INTRODUCTION}

Light transfer in snow is a major issue in snow energy balance, particularly in snowmelt and snow ecology investigations. It is important to know the amount of radiation that penetrates the snow cover, because biological and physical processes depend on it. Snow thermodynamic models require information on the absorption of radiation with depth in a snowpack. Solar and atmospheric heat transfer into the air/snow interface raises the temperature in a thin surface layer of the snowpack to its melting point before melting starts. A wet snow layer will eventually form, in which liquid water and snow grains coexist at $0^{\circ} \mathrm{C}$ (Tseng and others, 1994). When snow grains begin to melt in the wet snow layer, part of the snowpack will eventually lose its hardness and become fragile. Finally, the entire snowpack will be in the melting stage and become very fragile. Under clear skies, direct solar radiation predominates over diffuse radiation, and melting is dominated by direct solar radiation (Baker and others, 1999).

Light transmittance is determined by scattering and absorption, which are dependent on a combination of snow properties and snow thickness. In a snowpack, there is a multitude of air/ice interfaces to scatter light, and in the visible wavelengths scattering predominates over absorption (Warren, 1982). Transmittance is expected to fall exponentially with depth, but close to the surface there is a transitional region where nonexponential behaviour is found (Beaglehole and others, 1998). Optically active impurities in the snowpack can significantly reduce visible and near-infrared (NIR) reflectance, and thus in large amounts they influence the transmittance. Light transmission through the snow cover under natural conditions is not yet fully understood, although several studies have been published (Giddings and LaChapelle, 1961; Brandt and Warren, 1993; Beaglehole and others, 1998; Gerland and others, 2000; Hamre and others, 2004; Meirold-Mautner and Lehning, 2004; Warren and others, 2006; Perovich, 2007). This is mainly because the optical properties of snow change along with the evolution of the snow cover, and it is also a challenging task to deploy a spectroradiometer into the snowpack without disturbing the snow. The spectroradiometer may also disturb the light field or cause eccentric reflections.
Floating snow-covered ice - sea and lake ice - is a specific environment in which radiation penetration through the snow warms the ice and initiates internal melting and primary production. When the radiation reaches the water under the ice, convection and spring bloom development are initiated (Kelley, 1997; Ikävalko, 1998; Thomas and Papadimitriou, 2003; Arst and others, 2006; Salonen and others, 2009; Leppäranta and others, 2010). To examine light transfer in this environment, experimental work was conducted in the Baltic Sea and lake Kilpisjärvi, northern Finland. The effects of snow depth, wetness of snow, snow density and snow crystal properties on transmittance are discussed, including the influence of measurement technology. A new approach to placing a spectroradiometer into the snowpack is introduced.

\section{METHOD AND INSTRUMENTS}

\subsection{Field sites}

During the winters/springs of 2008 and 2009, a total of ten measurement sets were collected, including 22 light transmission measurements using a spectroradiometer. Three sets (index A) were conducted on the sea ice in the Bay of Bothnia, Baltic Sea $\left(64^{\circ} \mathrm{N}, 22^{\circ} \mathrm{E}\right)$, during our sea-ice campaign on R/V Aranda. Seven sets (indices B and C) were collected on the ice of lake Kilpisjärvi $\left(69^{\circ} \mathrm{N}, 20^{\circ} \mathrm{E}\right)$, which is located in the tundra zone at the northwestern tip of Finland. All B-set measurements were performed at the same site. The distances between snow pits were several metres. C1 was measured 1 year earlier and the site was $1 \mathrm{~km}$ northwest of site B. The measurements are summarized in Table 1. Diffuse light conditions mean that there were clouds and the sun was no longer visible behind them. Direct light conditions mean that the sun's direction was clear, so that direct radiation was received when the measurements were performed.

\subsection{Instruments}

The spectroradiometer was manufactured by Edmund Optics Inc., Barrington, NJ, USA. The wavelength range is $380-1050 \mathrm{~nm}$, the spectral resolution is $1.5 \mathrm{~nm}$ and measurement sensitivity is $0.002 \mu \mathrm{W} \mathrm{cm} \mathrm{cm}^{-2}$. Transfer of 


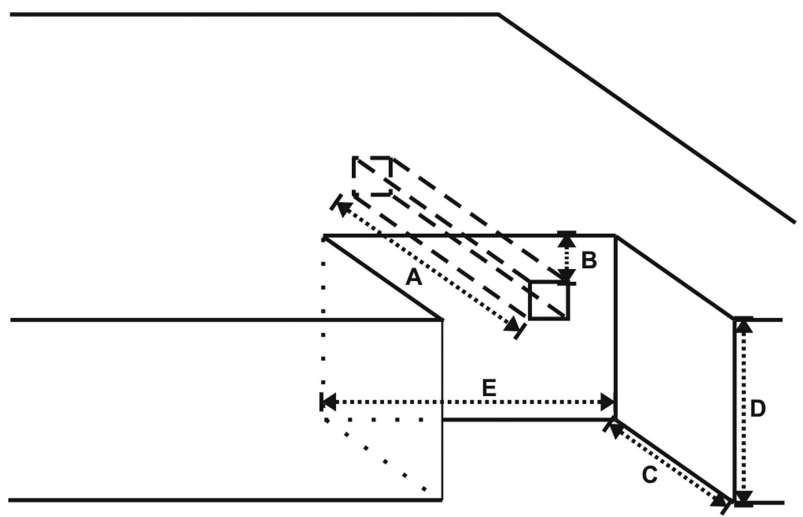

Fig. 1. A schematic picture describing how the tunnel was dug. The tunnel length $(A)$ was at least twice the snow-cover thickness (B). The tunnel opening was $10 \mathrm{~cm} \times 13 \mathrm{~cm}$. The snow-pit dimensions (C, D, E) were $1 \mathrm{~m} \times 1 \mathrm{~m} \times 1 \mathrm{~m}$.

photosynthetically active radiation (PAR; spectral band 400$700 \mathrm{~nm}$ ) through the snowpack was recorded by installing small (115 mm length, $18 \mathrm{~mm}$ diameter) scalar irradiance sensors (MDS-L) manufactured by Alec Electronics Co. Ltd, Tokyo, Japan, into the snowpack. The sensors were calibrated by the manufacturer for downwelling scalar quantum irradiance in the PAR band.

\subsection{Measurement methods}

A horizontal tunnel was dug, with the aid of a square metal container with open ends, for the spectroradiometer, which was then placed at the end of the tunnel (Fig. 1). The tunnel was closed with a piece of foam plastic, and a cardboard plate was used to prevent leakage from the open wall of the snow pit. The tunnel length was chosen so that the incoming radiation to the open wall of the snow pit would not disturb the radiation field inside the snowpack. The tunnel length was at least twice the snow-cover thickness, making wall corrections unnecessary (Bohren and Barkstrom, 1974). The measuring sequence, incident-transmitted-incident-transmitted-incident irradiance, was applied at every depth since we had only one spectroradiometer in use. It required about $1 \mathrm{~min}$ to do the full sequence. Average values for the incoming and transmitted spectral irradiance were calculated and were used to determine the transmittance and
Table 2. Snow crystal codes

\begin{tabular}{lc}
\hline Code & Description \\
\hline PPco & Columns (precipitation particle) \\
PPnd & Needles (precipitation particle) \\
DFdc & Partly decomposed precipitation particles \\
DFbk & Wind-broken precipitation particles \\
RGlr & Large rounded particles \\
RGxf & Faceted rounded particles \\
FCxr & Rounding faceted particles \\
MFpc & Rounded polycrystals \\
MFsl & Slush \\
IFil & Ice layer
\end{tabular}

extinction coefficient. Only the measurement sets in which the spectral standard deviation of the incident irradiance was $<5 \%$ of the average incident irradiance value were accepted (the standard deviation of the irradiance had a spectral shape similar to that of the mean incoming irradiance). A new tunnel was also dug for each depth.

The PAR sensors were deployed close to site $C$ on 23 April 2009 at 14.20 and retrieved on 27 April 2009 at 13.40 $(\mathrm{UTC}+3 \mathrm{~h})$. Sensors recorded the incoming quantum irradiance at $10 \mathrm{~min}$ intervals. Three sensors were deployed at depths of 4,8 and $30 \mathrm{~cm}$, and one sensor was mounted above the snowpack.

The size and shape of the snow grains were determined using a magnifying glass and a mm-scale grid. The snow type classification follows The international classification for seasonal snow on the ground issued by the International Association for Cryospheric Sciences (IACS; Fierz and others, 2009) (Tables 2 and 3). Photographs were taken to visually confirm the shape and size of the snow grains. Hardness was measured using a hand test, and density was measured from snow samples, using a Pesola spring balance with $5 \mathrm{~g}$ resolution and a metal box of height $5 \mathrm{~cm}$ and volume $1 \mathrm{dm}^{3}$. Salinity was measured from the meltwater of these snow samples using a hand-held conductivity probe, which provides salinity of sea-water solutions. This was done because large amounts of solid salt crystals can affect the transmittance (Perovich, 1998). The snow samples were melted in pre-cleaned airtight containers.

Table 1. Summary of field measurements

\begin{tabular}{|c|c|c|c|c|c|c|}
\hline Index & Place & Date & Time* & Solar altitude & Solar noon & Cloudiness $^{\dagger}$ \\
\hline A1 & Bay of Bothnia & 4 Mar 2009 & $13: 50$ & $18^{\circ}$ & $12: 43$ & 4/8 (direct) \\
\hline $\mathrm{A} 2$ & Bay of Bothnia & 5 Mar 2009 & $15: 20$ & $14^{\circ}$ & $12: 43$ & 8/8 (diffuse) \\
\hline A3 & Bay of Bothnia & 9 Mar 2009 & $09: 25$ & $12^{\circ}$ & $12: 43$ & 8/8 (diffuse) \\
\hline B1 & Lake Kilpisjärvi & 22 Apr 2009 & $10: 20$ & $25^{\circ}$ & $13: 38$ & 2/8 (direct) \\
\hline B2 & Lake Kilpisjärvi & 23 Apr 2009 & $10: 30$ & $26^{\circ}$ & $13: 38$ & 6/8 (diffuse) \\
\hline B4 & Lake Kilpisjärvi & 25 Apr 2009 & 09:30 & $22^{\circ}$ & $13: 38$ & 8/8 (diffuse) \\
\hline B5 & Lake Kilpisjärvi & 27 Apr 2009 & 09:30 & $23^{\circ}$ & $13: 38$ & 7/8 (diffuse) \\
\hline B6 & Lake Kilpisjärvi & 27 Apr 2009 & $19: 15$ & $15^{\circ}$ & $13: 38$ & 6/8 (diffuse) \\
\hline $\mathrm{C} 1$ & Lake Kilpisjärvi & 19 Apr 2008 & $10: 00$ & $23^{\circ}$ & $13: 39$ & 1/8 (direct) \\
\hline
\end{tabular}

\footnotetext{
*Eastern European Time (EET)/Eastern European Summer Time (EEST) (UTC + 2/3).

${ }^{\dagger}$ 'Diffuse' indicates that the sun was no longer visible behind clouds; 'direct' indicates that the sun's direction was free of clouds, so that direct radiation was received when the measurements were performed.
} 


\subsection{Data processing}

The transmittance and extinction coefficient were calculated for each site from the average values of the measured sets of incident $F_{\downarrow}(0, \lambda)$ and transmitted $F_{\downarrow}(h, \lambda)$ spectral irradiance. We used the band $400-900 \mathrm{~nm}$, as outside this band the noise level was too high. The transmittance, $T$, is the fraction of the incident downwelling irradiance that is transmitted through the snow cover:

$$
T=\frac{F_{\downarrow}(h, \lambda)}{F_{\downarrow}(0, \lambda)} .
$$

The transmittance is easy to calculate and provides the light condition below a given depth in the snow cover. The extinction coefficient is not dependent on the snow depth, but instead on the physical properties of snow and, being an apparent optical property, also on the directional distribution of the incoming irradiance. It can be calculated, using the irradiance attenuation law, an analogue of the Bouguer-Lambert absorption law (Warren, 1982):

$$
F_{\downarrow}(h+\Delta h, \lambda)=F_{\downarrow}(h, \lambda) \exp ^{-k(\lambda) \Delta h},
$$

where $k(\lambda)$ is the diffuse extinction coefficient:

$$
k(\lambda)=-\frac{\mathrm{d} \ln F_{\downarrow}(\lambda)}{\mathrm{d} h} \approx \frac{1}{\Delta h} \ln \frac{F_{\downarrow}(h, \lambda)}{F_{\downarrow}(h+\Delta h, \lambda)},
$$

where $\Delta h$ is the measurement depth interval. Due to strong scattering in the snowpack, the irradiance always becomes diffuse with depth. The depth at which this holds is at the surface under overcast conditions, while under clear-sky conditions, and depending on the physical properties of the snow, $\sim 1 \mathrm{~cm}$ is usually sufficient (Warren and others, 2006). Above this diffuse, asymptotic zone, Equations (2) and (3) do not apply. The irradiance normally decreases faster in the nonasymptotic zone than in the asymptotic zone and is dependent on the light and boundary conditions (Bohren and Barkstrom, 1974). The asymptotic e-folding depth, $\varepsilon(\lambda)$, was also calculated. This corresponds to the depth of the snow that attenuates the diffuse radiation to $1 / \mathrm{e}(\sim 37 \%)$ :

$$
\varepsilon(\lambda)=\frac{1}{k(\lambda)} .
$$

The data from the PAR sensors were cleaned from spikes appearing during sunrise and sunset, due to the physical properties of the sensors. For comparison, the flux of light quanta or quantum irradiance was also calculated from the Edmund Optics VIS-NIR Compact Spectroradiometer spectral measurements, as defined by (Arst, 2003)

$$
q_{\mathrm{PAR}}=\int_{400}^{700} F_{\downarrow}(\lambda) \frac{\lambda}{h_{0} c_{0}} \mathrm{~d} \lambda,
$$

where $h_{0}$ is Planck's constant and $c_{0}$ is the speed of light.

\section{RESULTS}

\subsection{Bay of Bothnia (index A)}

The snow conditions were quite similar in all measurements (Fig. 2). The snow depth was $25 \mathrm{~cm}$ in $\mathrm{A} 1$, and $50 \mathrm{~cm}$ in $\mathrm{A} 2$ and $A 3$. The size of the crystals varied from 1 to $2 \mathrm{~mm}$, and the predominant grain type was DFbk (wind-broken precipitation particles). The density varied between 220 and $400 \mathrm{~kg} \mathrm{~m}^{-3}$ and was lower in the top part of the snowpack than in the bottom part, except for snow pit A2 where the bottom layer consisted of slush. The salinity level was $0.1 \mathrm{ppt}$ from 0 to $49 \mathrm{~cm}$, where the snow was still practically dry. It
Table 3. Hand test symbols

\begin{tabular}{lcc}
\hline Term & Hardness & Symbol \\
\hline Very low & Fist & $\mathrm{F}$ \\
Low & 4 fingers & $4-\mathrm{f}$ \\
Medium & 1 finger & $1-\mathrm{f}$ \\
High & Pencil & $\mathrm{P}$ \\
Very high & Knife blade & $\mathrm{K}$ \\
\hline
\end{tabular}

is not clear whether the salts were crystallized or in tiny liquid water inclusions, but their volume was low and did not appear to affect the transmittance. The highest value, $0.5 \mathrm{ppt}$, was measured at the bottom of the snowpack (49$55 \mathrm{~cm}$ ), where all the snow was turned into slush (and excluded from the present measurements).

The transmittance varied from $\sim 0.5 \%$ to $7.5 \%$ in $\mathrm{A} 1$ and from $\sim 0.1 \%$ to $7 \%$ in $\mathrm{A} 2$ and A3 (Fig. 3). The lowest values were in the NIR band $(750-900 \mathrm{~nm})$ at $12 \mathrm{~cm}(\mathrm{~A} 2)$. The maximum value, $7.5 \%$ (A1), was measured at $640 \mathrm{~nm}$ at $4 \mathrm{~cm}$ under almost clear-sky conditions, when direct sunlight was also received at the site. At $8 \mathrm{~cm}$, the peak wavelength shifted to $580 \mathrm{~nm}$. Under diffuse light conditions, there was no clear peak at any depth. The extinction coefficient (Fig. 3) was in the range $0.65-0.8 \mathrm{~cm}^{-1}(0-4 \mathrm{~cm}$ layer), $0.2-0.4 \mathrm{~cm}^{-1}(4-8 \mathrm{~cm}$ layer $)$ and $0.14-0.5 \mathrm{~cm}^{-1}$ (8-12 cm layer) in the visible band $(400-750 \mathrm{~nm})$. Although there was abundant measurement noise in the NIR band, we noted that the transmittance decreased to almost zero at $12 \mathrm{~cm}$ (A2). The e-folding depth varied between 1.3 and $1.5 \mathrm{~cm}(0-4 \mathrm{~cm}$ layer $), 2.5$ and $5 \mathrm{~cm}(4-8 \mathrm{~cm}$ layer $)$ and 2 and $7.1 \mathrm{~cm}(8-12 \mathrm{~cm}$ layer) in the visible band. The local minimum at $760 \mathrm{~nm}$ was due to absorption by water vapour molecules in the air.

\subsection{Kilpisjärvi (indices $B$ and $C$ )}

The wetness of the snowpack varied daily in winter 2009 (index B) (Fig. 4). In the afternoon, the entire snowpack was wet, but in some mornings (B4 and B5) the snowpack was quite dry in the top layer, because the air temperature decreased to $<0^{\circ} \mathrm{C}$ during the night. In the evening (B6), the top layer was already refrozen when we initiated the measurements. The grain size varied between 1 and $3 \mathrm{~mm}$, and the predominant shapes were RGxf (faceted rounded particles) and MFpc (rounded polycrystals). Set C1 (Fig. 4) was measured 1 year earlier and the physical properties of the snow differed from those in winter 2009. The snow density was clearly lower, but the grain shape and size were quite similar.

The profiles of the transmittance and extinction coefficient show features quite similar to those in the Bay of Bothnia. In the NIR band, there was usually abundant measurement noise, and under diffuse light conditions there was no clear peak at any depth. Measurements B4, B5 and B6 are shown in the same panels because the physical properties of the snowpack and light conditions were similar in these measurements. The difference between the transmittance at 4 and $8 \mathrm{~cm}$ was clearly smaller when the snow was wet (B2 and B3) than when it was dry (B5 and B6). In winter 2009 (index B; Figs 5 and 6), the transmittance varied between $3 \%$ and $27 \%(0-4 \mathrm{~cm}$ layer $)$ and $<1 \%$ and $16 \%(0-$ $8 \mathrm{~cm}$ layer). The extinction coefficient varied between 0.35 

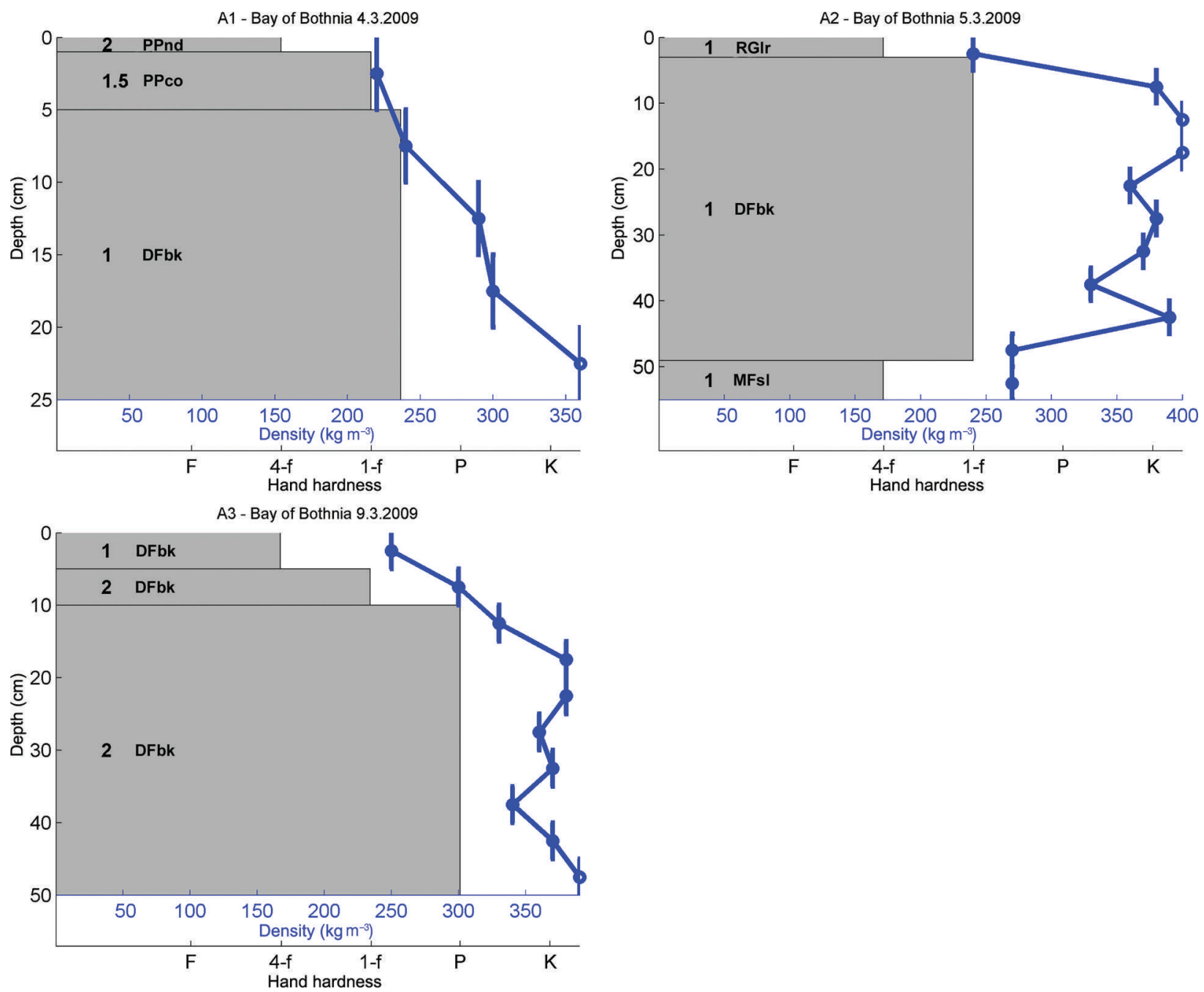

Fig. 2. Snow-pit profiles from the Bay of Bothnia in 2009. Dates are day.month.year. The number before the snow crystal code indicates the crystal size $(\mathrm{mm})$.
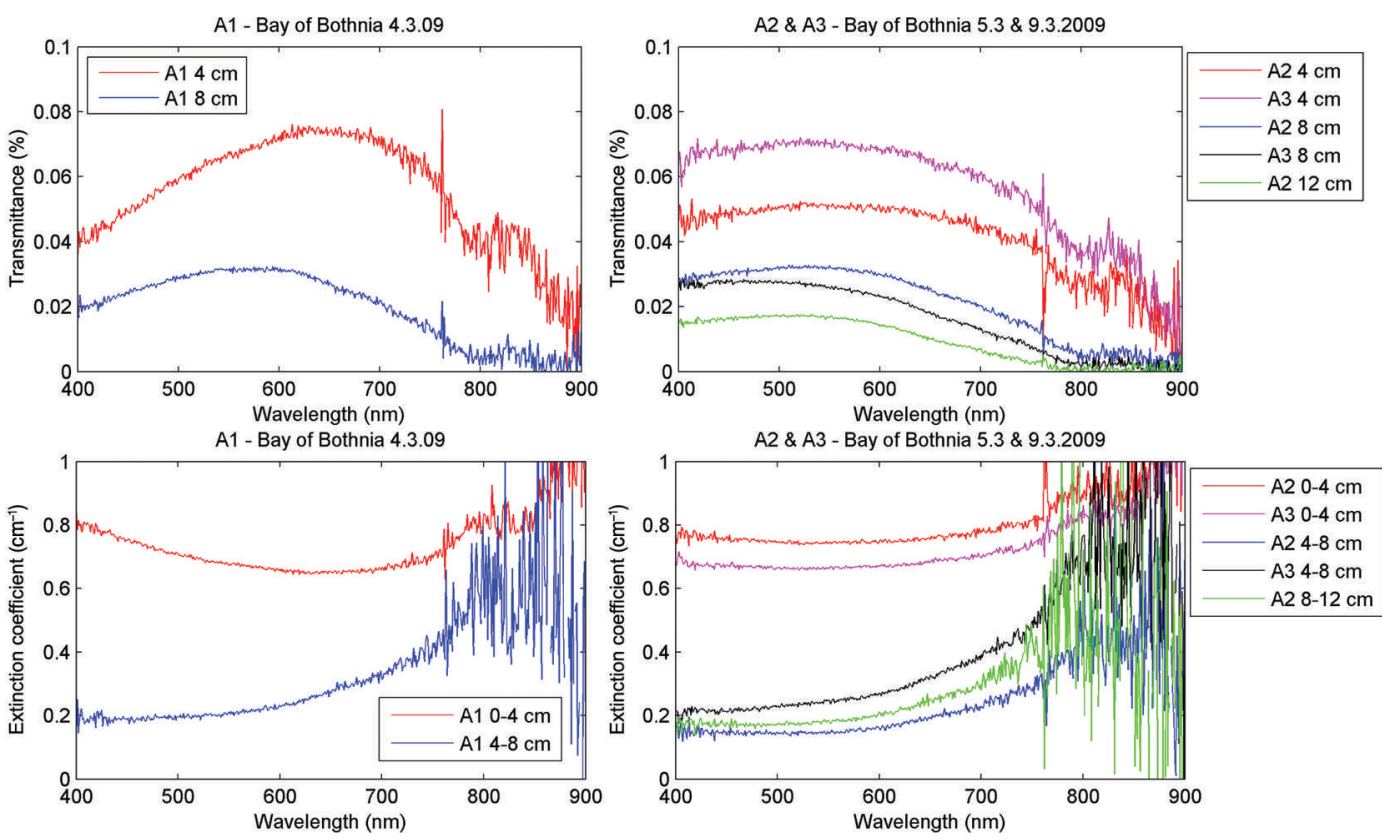

Fig. 3. Indices A1-A3: transmittance and extinction coefficient values from Bay of Bothnia in 2009. Dates are day.month.year. A2 and A3 are plotted in the same panels, because the physical properties of the snowpack and light conditions were similar in both measurements. 

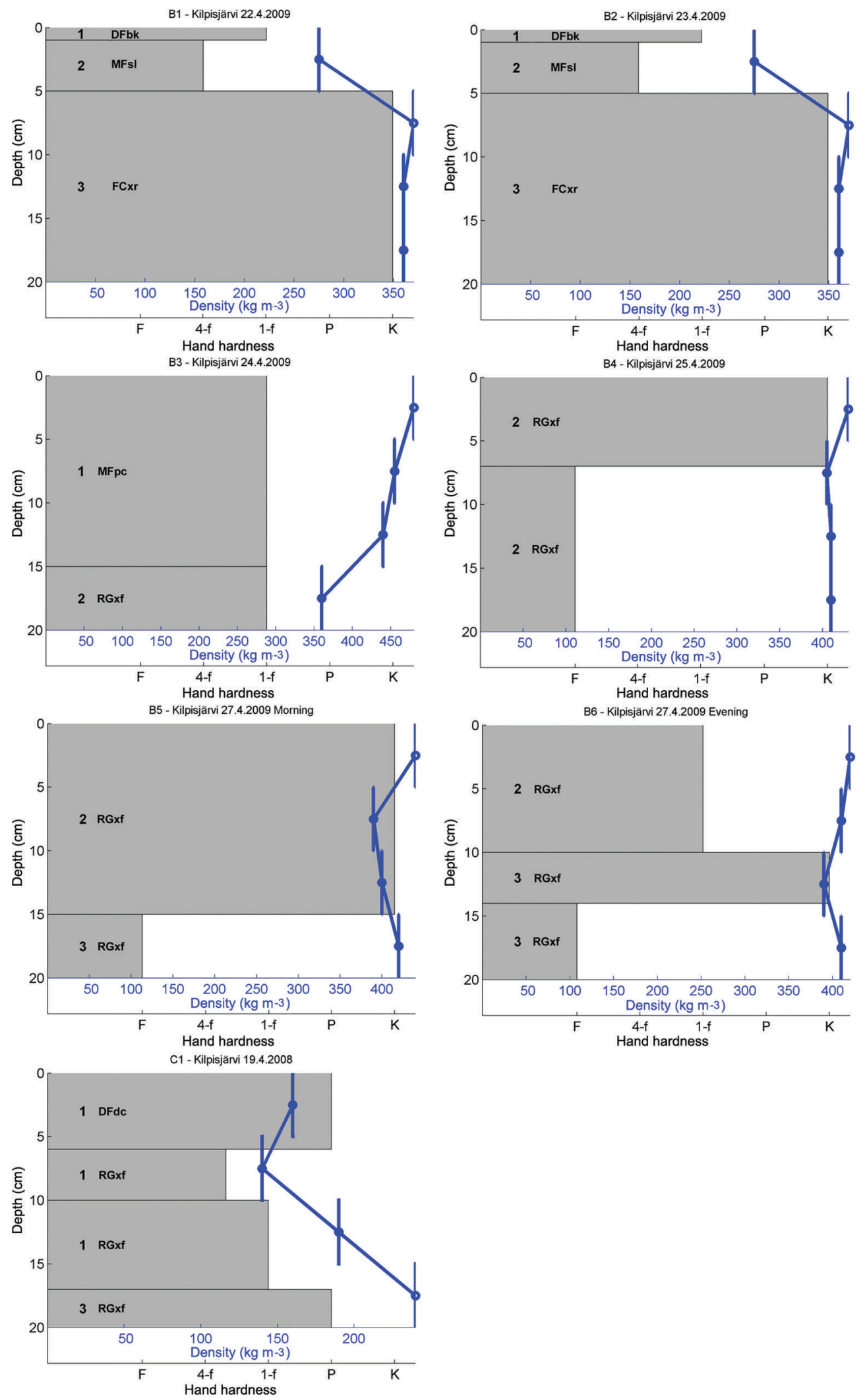

Fig. 4. Snow-pit profiles from Kilpisjärvi in 2009 (index B) and 2008 (index C). Dates are day.month.year. The number before the snow crystal code indicates the crystal size $(\mathrm{mm})$.

and $0.8 \mathrm{~cm}^{-1}(0-4 \mathrm{~cm}$ layer $)$ and 0.03 and $0.4 \mathrm{~cm}^{-1}(4-8 \mathrm{~cm}$ layer). The e-folding depth varied between 1.25 and $2.9 \mathrm{~cm}$ $(0-4 \mathrm{~cm}$ layer) and 2.5 and $33 \mathrm{~cm}(4-8 \mathrm{~cm}$ layer). In $\mathrm{C} 1$ (Fig. 7) the transmittance varied between $40 \%$ and $80 \%(0$ $4 \mathrm{~cm}$ layer), $20 \%$ and $40 \%(0-8 \mathrm{~cm}$ layer) and $<1 \%$ and $20 \%$ $(0-12 \mathrm{~cm}$ layer). The extinction coefficient varied between 0.07 and $0.3 \mathrm{~cm}^{-1}(0-4 \mathrm{~cm}$ layer $), 0.13$ and $0.35 \mathrm{~cm}^{-1}$
(4-8 $\mathrm{cm}$ layer) and 0.14 and $0.40 \mathrm{~cm}^{-1}(8-12 \mathrm{~cm}$ layer $)$. The e-folding depth varied between 2.5 and $14 \mathrm{~cm}(0-4 \mathrm{~cm}$ layer), 2.9 and $7.7 \mathrm{~cm}(4-8 \mathrm{~cm}$ layer $)$ and 2.5 and $7.1 \mathrm{~cm}$ (8-12 cm layer). Sets B1 and C1 had direct light conditions and the other sets had diffuse light conditions. The strange transmittance profiles in set B1 were due to change in light conditions between the measurement depths. 

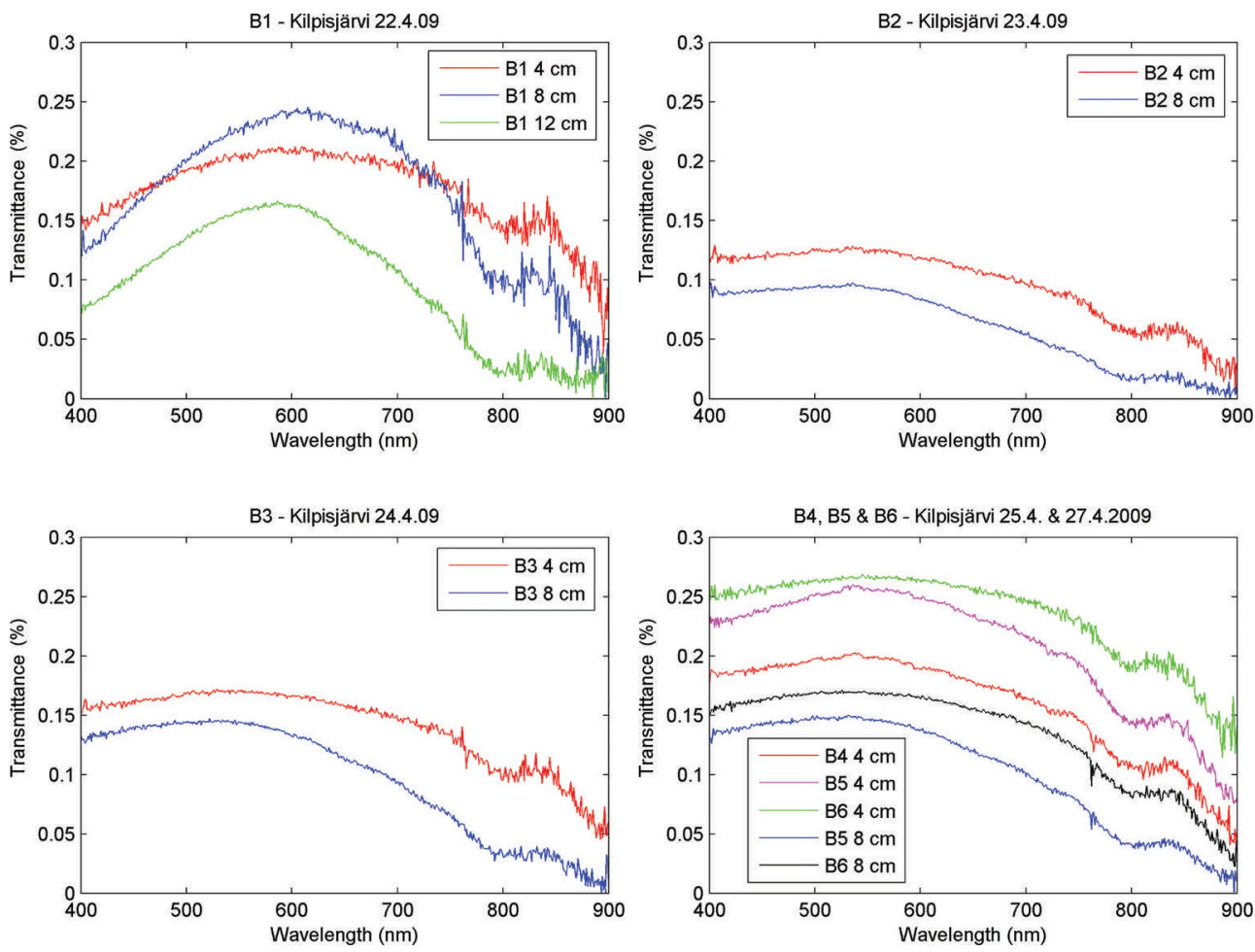

Fig. 5. Indices B1-B6: transmittance values from Kilpisjärvi in 2009. Dates are day.month.year. B4, B5 and B6 are plotted in the same panel, because the physical properties of the snowpack and light conditions were similar.

The PAR sensors, deployed at 4 and $8 \mathrm{~cm}$, were tilted when they were retrieved, so the data of these sensors were not used. The snow had melted considerably around them, causing the tilting, because the sensors absorbed a substantial amount of radiation and thus generated heat. The PAR sensor at $30 \mathrm{~cm}$ was the only one in good condition, since it was vertically oriented throughout the experiment. The results from the PAR sensor measurements at $30 \mathrm{~cm}$ are shown in Figure 8 . The data gaps indicate nighttime. The daytime maximum values at $30 \mathrm{~cm}$ were $\sim 400$ $\mu \mathrm{mol} \mathrm{m} \mathrm{m}^{-2} \mathrm{~s}^{-1}$, or $\sim 80 \mathrm{Wm}^{-2}$. The transmittance increased from $10 \%$ to $20 \%$ in 4 days. The extinction coefficient varied
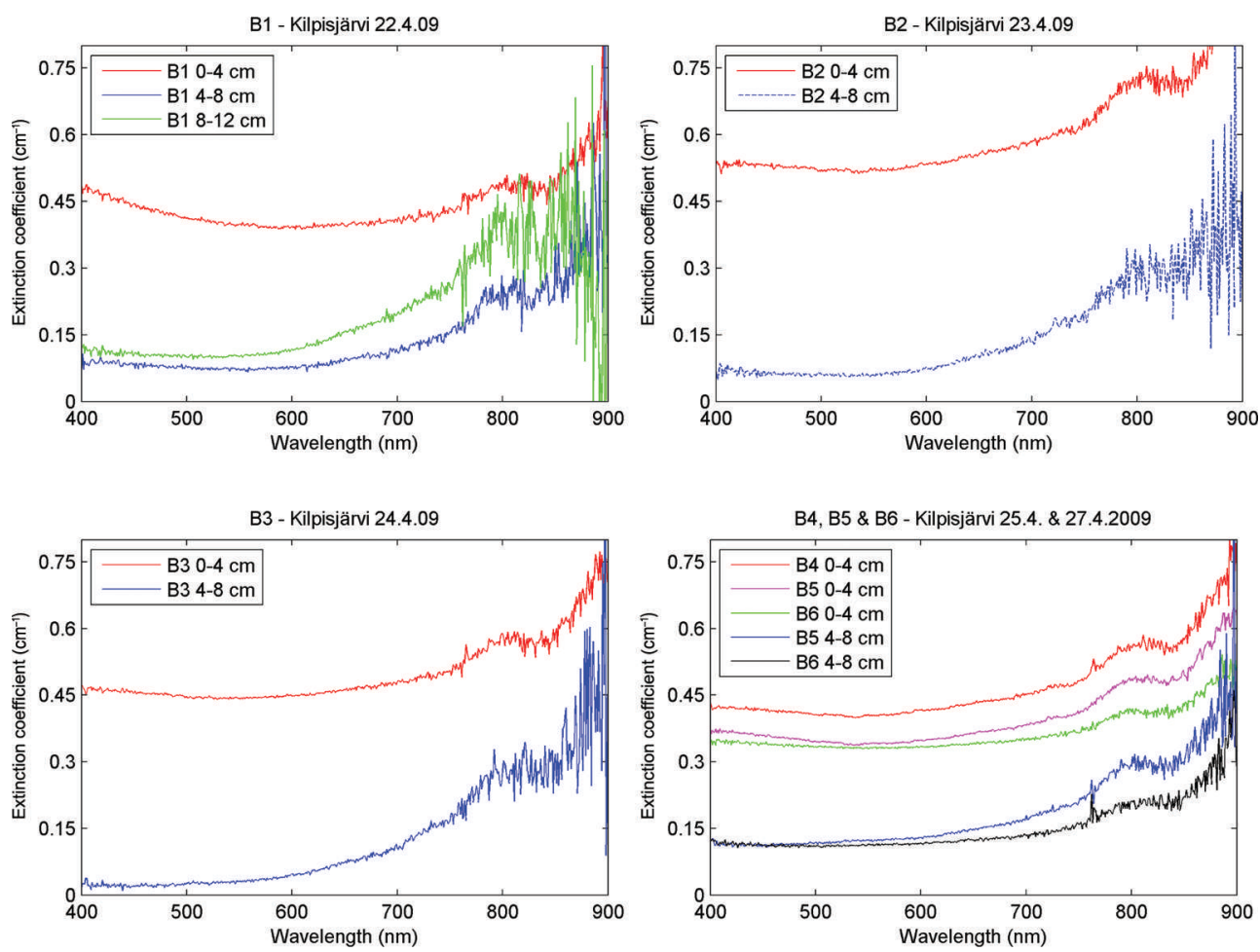

Fig. 6. Indices B1-B6: extinction coefficient values from Kilpisjärvi in 2009. Dates are day.month.year. B4, B5 and B6 are plotted in the same panel, because the physical properties of the snowpack and light conditions were similar. 

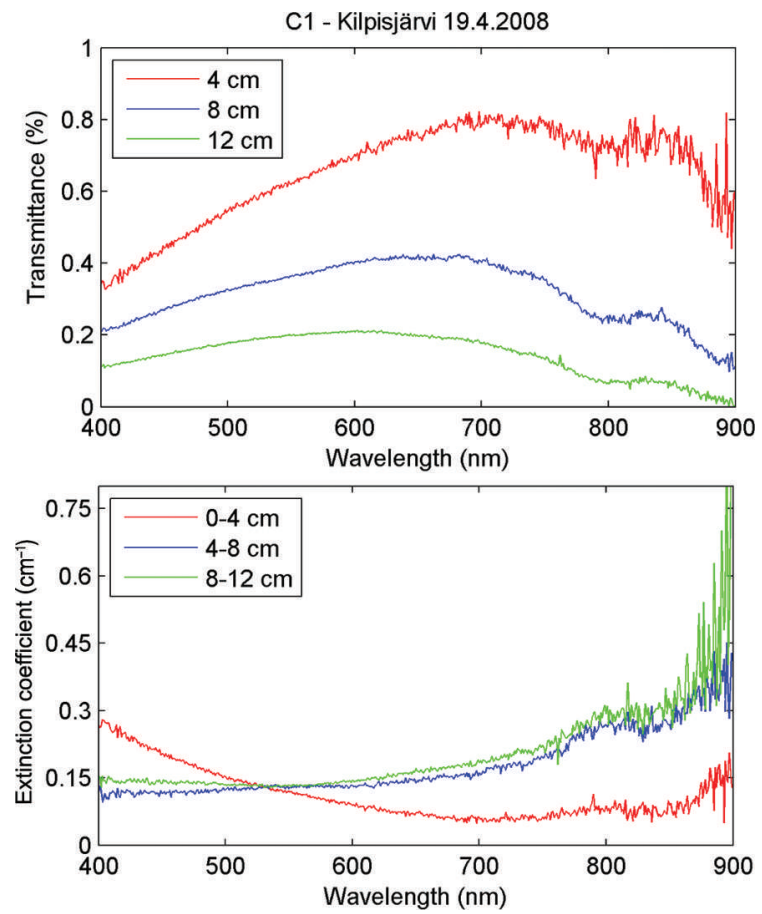

Fig. 7. Index $\mathrm{C} 1$ : transmittance and extinction coefficient values from Kilpisjärvi in 2008.

between 0.05 and $0.08 \mathrm{~cm}^{-1}$, and e-folding varied between 12 and $20 \mathrm{~cm}$. At this site, the top part of the snowpack turned into slush during the day and froze partially during the night. The snow crystals were different from those at location B, where we performed all the spectroradiometer measurements. The snow-pit profile from the PAR sensor's location is shown in Figure 8.

\subsection{Comparison between sea-ice and lake sites}

The grain size and shape were quite similar within the lake sites and sea site locations, but varied widely between these locations. The snow densities measured in the upper part of the snowpack were slightly higher in Kilpisjärvi than in the Bay of Bothnia, except at C1. The grain size in Kilpisjärvi in 2009 slightly exceeded that in 2008 and in the Bay of Bothnia. The grain type differed between the two locations. In the Bay of Bothnia, highly broken particles predominated in the snowpack, while in Kilpisjärvi the rounded mixed form predominated. The measurements at Kilpisjärvi were performed almost 2 months later in springtime, which explains why the snowpack in the Bay of Bothnia was drier than that in Kilpisjärvi. The transmittance values varied substantially between the two locations and were higher in Kilpisjärvi, and there was also clear day-to-day variation. The extinction coefficient and e-folding depth varied significantly between locations and thus between snow conditions.

\section{LIGHT CONDITIONS IN SNOW COVER}

We observed clear differences in the transmittance profiles between diffuse (Fig. 3: A2 and A3 and Fig. 5: B2-B6) and direct (Fig. 3: A1, Fig. 5: B1, and Fig. 7: C1) light conditions, especially at $4 \mathrm{~cm}$, because under direct light conditions the radiation field is not yet totally diffuse at this depth. At greater depths, where the radiation field is diffuse, the
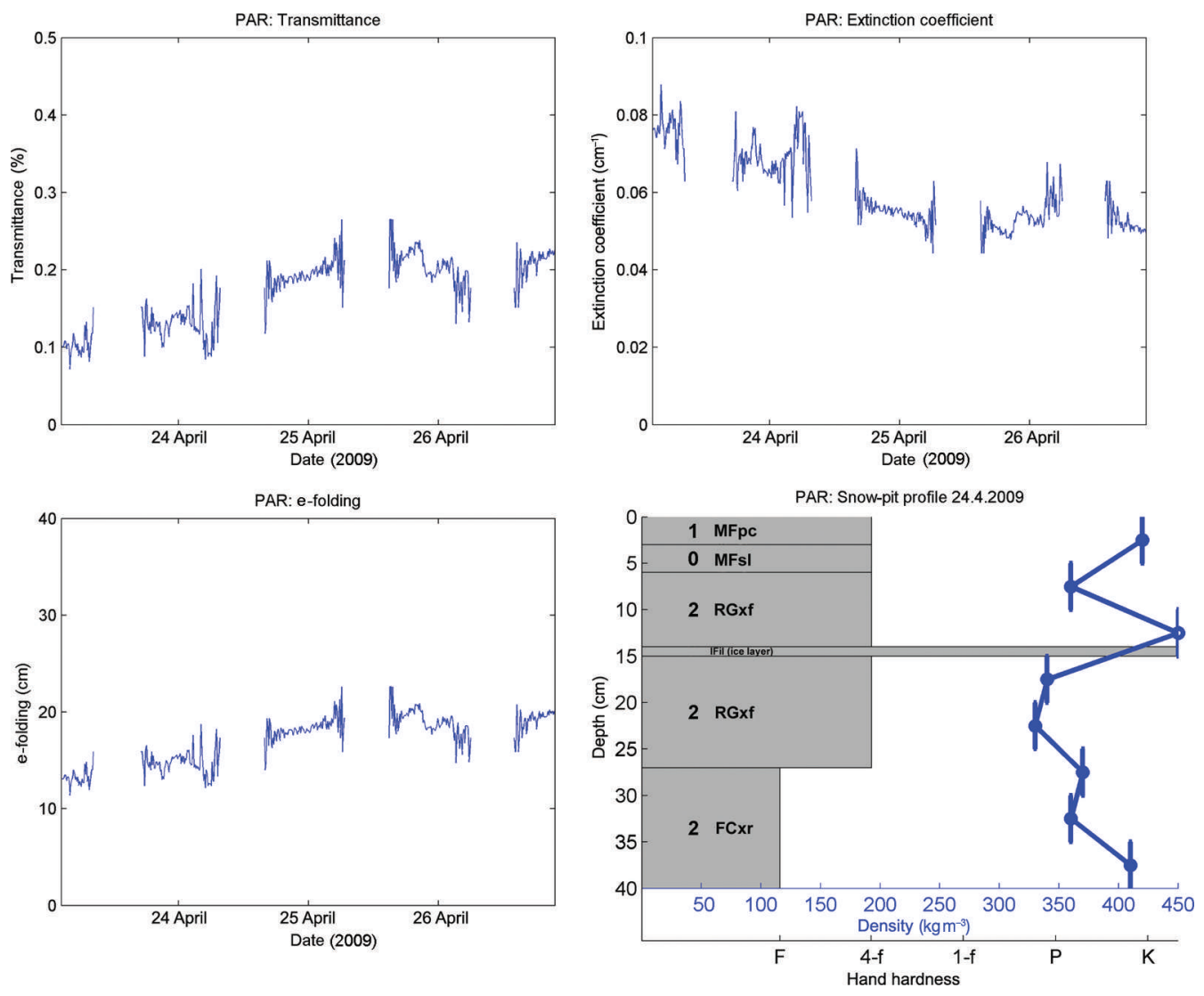

Fig. 8. Results from the PAR sensor measurements at $30 \mathrm{~cm}$ in Kilpisjärvi in 2009 . Dates are day/month/year. The zero at $5 \mathrm{~cm}$ indicates that the size of the grains could not be measured, because the snow had become slush. 


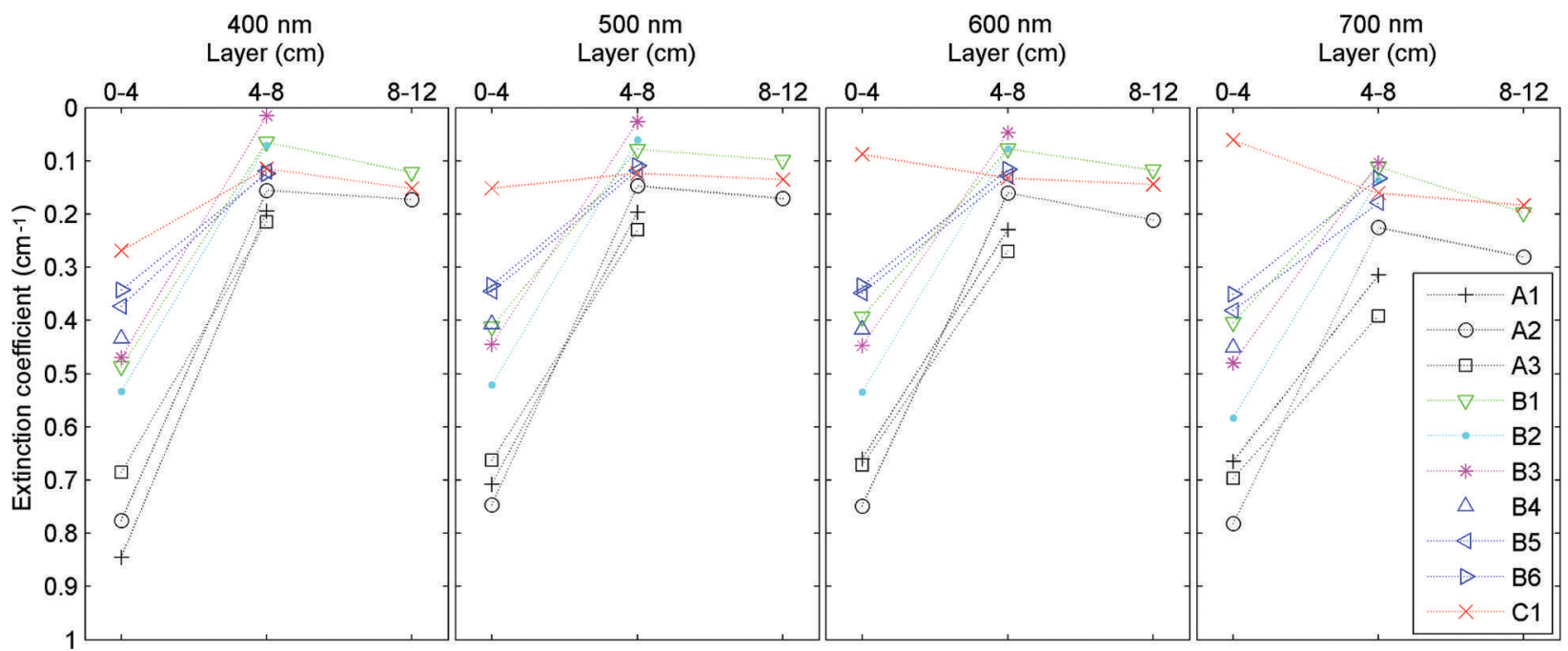

Fig. 9. Summary of extinction coefficient point values at 400,500, 600 and $700 \mathrm{~nm}$. Black markers indicate Bay of Bothnia, and other colours Kilpisjärvi.

transmittance profiles are more similar. The strange transmittance profiles in set B1 are explained by change in the incoming radiation between measurements. Among the measurement sequences, the light condition changed from diffuse to direct (during the measurements at $4 \mathrm{~cm}$, there was a cloud shadowing the sun). Therefore, the transmittance profile at $4 \mathrm{~cm}$ is different from the profiles at 8 and $12 \mathrm{~cm}$. B1 is shown here to demonstrate the types of problems that arise when measuring outside. The salinity levels were low (index A) in the upper part of the snowpack and thus presumably did not affect the irradiance values. The high transmittance values in set $\mathrm{C} 1$ are probably due to the low snow density (freshly fallen snow) and direct light conditions. The highest e-folding depths were in the visible band, and the lowest in the NIR band.

The largest extinction coefficient is located in the NIR band (750-900 nm), and the lowest in the visible band (400$750 \mathrm{~nm}$ ). Under direct light conditions (Fig. 3: A1, Fig. 6: B1, and Fig. 7: C1) at $4 \mathrm{~cm}$, the minimum shifted to longer wavelengths close to the NIR band $(700 \mathrm{~nm})$. This is probably because Equation (3) is not applicable at $4 \mathrm{~cm}$ where the radiation field is not yet diffuse due to the low density. Warren and others (2006) reported that $1 \mathrm{~cm}$ is usually sufficient, but this applies to the snowpack in Antarctica, where the density of the snowpack is much higher and the grain size is smaller. In the layers at $4-8$ and $8-12 \mathrm{~cm}$, the extinction coefficient profiles are quite similar between direct and diffuse light conditions. In the $4-8 \mathrm{~cm}$ layer in indices A3 (Fig. 3) and C1 (Fig. 7), there is a clear minimum close to $400 \mathrm{~nm}$. A summary of the extinction coefficients at four wavelengths $(400,500,600$ and $700 \mathrm{~nm})$ is shown in Figure 9. We observed that in the visible band the values from the Bay of Bothnia were quite similar. The values from Kilpisjärvi are bundled in the deeper layers, 4-8 and $8-12 \mathrm{~cm}$, but in the $0-4 \mathrm{~cm}$ layer there are wide differences between the measurement sets, especially measurement set $\mathrm{C} 1$, which stands out at every depth. The difference in extinction coefficients between the Bay of Bothnia (index A) and Kilpisjärvi (indices B and C) can probably be explained by differences in density and predominant grain types. The extinction coefficients are almost twice as high in the Bay of Bothnia as in Kilpisjärvi.
The increase in transmittance of PAR at $30 \mathrm{~cm}$ during the measurement period was probably caused by snowmelt. During the first 2 days the snow melted $4 \mathrm{~cm}$, and the total ablation during the 4 days was $7 \mathrm{~cm}$. The increase in transmittance was also influenced by the increased amount of free liquid water in the snowpack. The extinction coefficient varied between 0.04 and $0.08 \mathrm{~cm}^{-1}$. Extinction coefficients are shown in Figure 10 for the flux of light quanta in the PAR band $(400-700 \mathrm{~nm})$ calculated from the spectroradiometer measurements from Kilpisjärvi in 2009 (index B). The extinction coefficient values were calculated for two snow layers, from 0 to $4 \mathrm{~cm}$ and from 4 to $8 \mathrm{~cm}$. They varied between 0.04 and $0.13 \mathrm{~cm}^{-1}$. The extinction coefficients from the B1, B2 and B3 measurements in the $4-8 \mathrm{~cm}$ layer were in the same range as the extinction coefficient from the PAR sensor measurement: $0.08,0.07$ and $0.04 \mathrm{~cm}^{-1}$ and $0.04-0.08 \mathrm{~cm}^{-1}$, respectively.

\section{DISCUSSION}

The possible sources of error that can affect measured irradiance values include leakage from the tunnel/open wall, tilted sensor (not placed horizontally/vertically) and the spectroradiometer itself. To determine whether the open wall of the snow pit significantly affects the downwelling irradiance, we performed the following test. When the spectroradiometer was placed, the irradiance was measured; immediately after that the snow pit was quickly filled and the irradiance measured again. This sequence was repeated several times, and there was no clear difference between the results with the filled snow pit and the open snow pit. This showed that when the tunnel length is at least twice the thickness of the snow cover above the tunnel, there is no significant leakage through the open wall or from the sealed tunnel, especially when the open wall of the snow pit is covered with a cardboard plate. Placing the sensor exactly in a horizontal (spectroradiometer) or vertical (PAR) position every time is tricky. Although it cannot be placed in exactly the same way each time, we believe that these small changes in position caused no substantial changes in the measured irradiance values. Possible light leakage from one wavelength to another within the spectroradiometer may also be a major 
source of error. Light leakage can cause substantial variations in measured irradiance values. The integration time varied between 9 and $200 \mathrm{~ms}$. Long integration times resulted in better signal-to-noise ratios in the NIR band, but in some cases longer integration times caused saturation in the visible band. Therefore, a shorter integration time was used, which caused some noise in the NIR band. This was an unexpected problem with the Edmund Optics spectroradiometer.

The spectral profiles of the extinction coefficient were similar to what Meirold-Mautner and Lehning (2004) reported. In most of their profiles, there was no sharp distinct minimum but rather a minimal band, and at shallow depths this band shifted to longer wavelengths close to the NIR band. This was because extinction at shallow depths did not follow an exponential decrease. Perovich (2007) also reported similar results. The spectral profiles of the extinction coefficient that he reported were similar to those from the Bay of Bothnia and Kilpisjärvi. Warren and others (2006) reported that the absorption minimum for pure snow was at $390 \mathrm{~nm}$ in Antarctica. In some of our measurement sets, the minimum was close to $400 \mathrm{~nm}$. Most likely the spectral shift to longer wavelengths was due to impurities in the snow. There is much more soot, as well as other impurities, in snow in Finland than in Antarctica, because of pollution from industry and automobiles. Impurities in the snowpack will shift the absorption minimum to longer wavelengths (Warren and others, 2006). It may be possible to use spectral shifts to estimate the amount of impurities in a snowpack. PAR sensor results are useful for snow ecology investigations, since they provide information on light quanta available in and under snow. In aquatic ecology, the euphotic depth is usually referred to as the depth at which the irradiance is $1 \%$ of the downwelling irradiance at the surface (e.g. Arst, 2003). Using this principle, the depth at which the number of photons is insufficient for primary production in a snowpack is

$$
z_{\mathrm{e}}=\frac{1}{k_{\mathrm{PAR}}} \log [100(1-\alpha)]
$$

where $k_{\text {PAR }}$ is the representative extinction coefficient in the PAR band. For $k_{\text {PAR }} \sim 0.1 \mathrm{~cm}^{-1}$ and $\alpha \sim 0.7$, we obtain $z_{\mathrm{e}} \sim 30 \mathrm{~cm}$.

Snow cover protects the sea ice or lake ice underneath by reducing warming and deterioration of the ice sheet. This reduction is due to both high albedo and high light extinction coefficient of snow. In the present data, extinction of light was stronger in the Bay of Bothnia case. In dry snow, the light level at $10 \mathrm{~cm}$ depth was $<5 \%$ in the Bay of Bothnia and $20 \%$ in Kilpisjärvi as compared with the net incoming radiation at the surface. Extinction was also stronger in the surface layer of snow, which makes dry snow a very good protector even when thin. But in the course of the melting season, albedo and extinction coefficient both decrease when liquid water content in snow increases, so the melting front catches the ice surface where a thin layer of snow remains. Thus, in thermodynamic modelling of ice, extinction of light in the snow layer requires a depth- and timedependent coefficient for realistic energy balance.

\section{CONCLUSIONS}

Spectral measurements of solar radiation in the 400-900 nm band were performed in the snow cover in two locations in Finland: on sea ice and on lake ice. A spectroradiometer

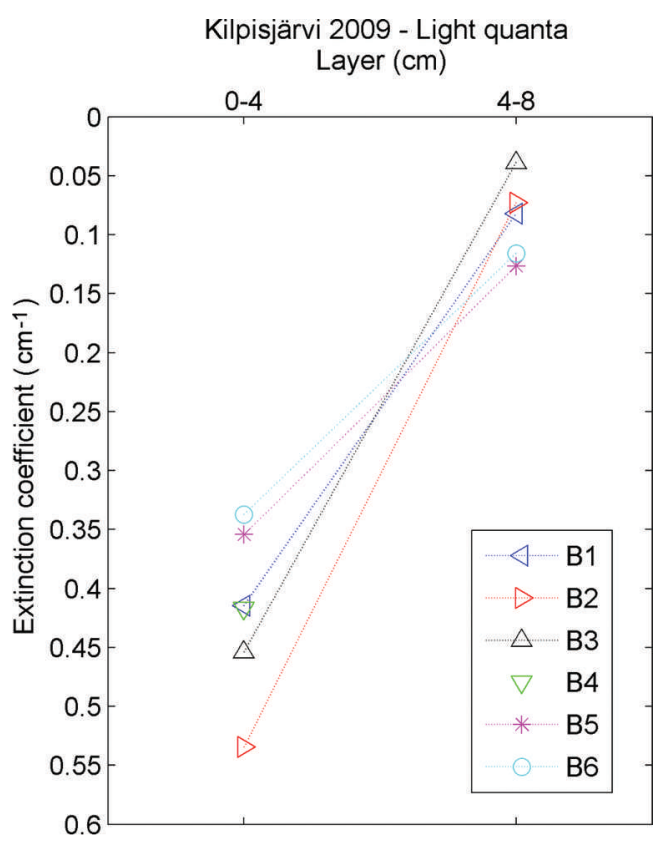

Fig. 10. Extinction coefficient values for the flux of light quanta in the PAR band $(400-700 \mathrm{~nm})$ from the spectral measurements (index B).

(wavelength range $380-1050 \mathrm{~nm}$ and spectral resolution $1.5 \mathrm{~nm}$ ) and a PAR sensor were used for the measurements. In addition to the light measurements, physical characterization of snow stratigraphy was done, including the thickness, density, hardness (hand test), salinity, and grain size and shape (photographs of crystals). Transmittance varied from $<1 \%(0-12 \mathrm{~cm}$ layer) to $80 \%(0-4 \mathrm{~cm}$ layer $)$, and the extinction coefficient was between $0.03 \mathrm{~cm}^{-1}(4-8 \mathrm{~cm}$ layer) and $0.8 \mathrm{~cm}^{-1}(0-4 \mathrm{~cm}$ layer $)$.

The substantial variations in the transmittance are accompanied by changes in snow density, snow grain size and type, and light conditions. The substantial variations in the extinction coefficient are accompanied by variations in the physical properties of the snowpack, as mentioned previously and because the light field was not diffuse in the first measured layer $(0-4 \mathrm{~cm})$ under clear-sky conditions. A major problem was how to place the spectroradiometer and the PAR sensor into the snowpack without disturbing the latter. One possibility is to build a horizontal platform before the snow falls and place the spectroradiometer under the platform (Perovich, 2007). This solves the problem of placing the sensor into the snowpack. But this measuring technique also has disadvantages. The measurement site must be chosen before the snow season, and the investigator must wait for the snow to accumulate. We used a square metal tube to dig the tunnel. With the aid of a metal container, every tunnel was the same and the walls of the tunnels were intact. In our opinion, there is, as yet, no perfect measuring technique for spectral radiation measurements within snowpack. Every technique has advantages and disadvantages.

Optical properties of snow cover on sea ice and lake ice are critical factors for the growth and deterioration of ice and primary production inside and below ice. The depth and time dependency of these properties need to be considered when parameterizing numerical models.

Measurement set B1 shows that measurements in controlled environments are needed. Our future work will 
focus on developing measurement techniques. This will also enable us to measure the irradiance from deeper parts of the snowpack. Measurements in a cold laboratory are also planned.

\section{ACKNOWLEDGEMENT}

This work was funded by the Academy of Finland (project 122787 Ice Laboratory and Ice Geophysics).

\section{REFERENCES}

Arst, H. 2003. Optical properties and remote sensing of multicomponental water bodies. Chichester, Springer-Praxis.

Arst, H., A. Erm, M. Leppäranta and M. Reinart. 2006. Radiative characteristics of ice-covered freshwater and brackish water bodies. Proc. Estonian Acad. Sci., Geol., 55(1), 3-23.

Baker, J.M., K.J. Davis and G.C. Liknes. 1999. Surface energy balance and boundary layer development during snowmelt. J. Geophys. Res., 104(D16), 19,611-19,621.

Beaglehole, D., B. Ramanathan and J. Rumberg. 1998. The UV to IR transmittance of Antarctic snow. J. Geophys. Res., 103(D8), 8849-8858.

Bohren, C.F. and B.R. Barkstrom. 1974. Theory of the optical properties of snow. J. Geophys. Res., 79(30), 4527-4535.

Brandt, R.E. and S.G. Warren. 1993. Solar-heating rates and temperature profiles in Antarctic snow and ice. J. Glaciol., 39(131), 99-110.

Fierz, C. and 8 others. 2009. The international classification for seasonal snow on the ground. Paris, UNESCO-International Hydrological Programme. (IHP Technical Documents in Hydrology 83.)

Gerland, S., G.E. Liston, J.G. Winther, J.B. Örbæk and B.V. Ivanov. 2000. Attenuation of solar radiation in Arctic snow: field observations and modelling. Ann. Glaciol., 31, 364-368.
Giddings, J.C. and E. LaChapelle. 1961. Diffusion theory applied to radiant energy distribution and albedo of snow. J. Geophys. Res., 66(1), 181-189.

Hamre, B., J.-G. Winther, S. Gerland, J.J. Stamnes and K. Stamnes. 2004. Modeled and measured optical transmittance of snowcovered first-year sea ice in Kongsfjorden, Svalbard. J. Geophys. Res., 109(C10), C10006. (10.1029/2003JC001926.)

Ikävalko, J. 1998. Further observations on flagellates within sea ice in northern Bothnian Bay, the Baltic Sea. Polar Biol., 19(5), 323-329.

Kelley, D.E. 1997. Convection in ice-covered lakes: effects on algal suspension. J. Plankton Res., 19(12), 1859-1880.

Leppäranta, M., A. Terzhevik and K. Shirasawa. 2010. Solar radiation and ice melting in Lake Vendyurskoe, Russian Karelia. Hydrol. Res., 41(1), 50-62.

Meirold-Mautner, I. and M. Lehning. 2004. Measurements and model calculations of the solar shortwave fluxes in snow on Summit, Greenland. Ann. Glaciol., 38, 279-284.

Perovich, D.K. 1998. The optical properties of sea ice. In Leppäranta, M., ed. Physics of ice-covered seas. Helsinki, University of Helsinki Press, 195-230.

Perovich, D.K. 2007. Light reflection and transmission by a temperate snow cover. J. Glaciol., 53(181), 201-210.

Salonen, K., M. Leppäranta, M. Viljanen and R.D. Gulati. 2009. Perspectives in winter limnology: closing the annual cycle of freezing lakes. Aquatic Ecol., 43(3), 609-616.

Thomas, D.N. and S. Papadimitriou. 2003. Biogeochemistry of sea ice. In Thomas, D.N. and G.S. Dieckmann, eds. Sea ice: an introduction to its physics, chemistry, biology and geology. Oxford, Blackwell Publishing, 267-302.

Tseng, P.H., T.H. Illangasekare and M.F. Meier. 1994. Modeling of snow melting and uniform wetting front migration in a layered subfreezing snowpack. Water Resour. Res., 30(8), 2363-2376.

Warren, S.G. 1982. Optical properties of snow. Rev. Geophys., 20(1), 67-89.

Warren, S.G., R.E. Brandt and T.C. Grenfell. 2006. Visible and nearultraviolet absorption spectrum of ice from transmission of solar radiation into snow. Appl. Opt., 45(21), 5320-5334. 